\title{
Features of functional dependence of random phenomena and values in social being in conditions of its unstability (the environmental position)
}

\author{
Lyubov Drotyanko ${ }^{1}$, Julia Kharchenko ${ }^{1, *}$, Sergej Kharchenko ${ }^{1}$, and Oleg Kolomiets ${ }^{1}$ \\ ${ }^{1}$ National Aviation University, Kosmonavta Komarova ave, 1, 03058, Kyiv, Ukraine
}

\begin{abstract}
The analysis of the phenomenon of "random" and the principle of the relationship of random phenomena in social reality in the conditions of its instability has been conducted. On this basis, the key task was the conceptualization of the random phenomena in the scales of typology of fundamental and social interactions. It has been confirmed that the concept of "random" in terms of instability is more effectively described through ontological, phenomenological, transcendental and functional approaches and in the context of environmental position. A probability principle was applied when describing the randomness of abstract values. It has been proved that even minor aberrations at one or another point of space at different systemic levels of the material world can profoundly change the metric properties of systems, cause their instability. The results of the research confirmed that the unstable social system does not return to the state of equilibrium from which it has came out for different reasons, but continuously it moves away from it or makes unacceptably large fluctuations around it. And functional dependence between random phenomena and quantities under conditions of social instability is possible as stability of a different kind.
\end{abstract}

\section{Introduction}

In modern philosophical science, social reality is presented as a super-complex system that is in dynamics, producing connections and relationships of varying strength between its numerous elements. These connections are both random and natural, and the structural elements are represented as an infinite number of variables. Such elements can be individuals, large (or small) groups of individuals. Connections also reflect the presence of various types of interaction between numerous components of the structure of social being. Sometimes this system is stable, but sometimes it shows instability.

Society is becoming more and more complex and a person is trying to adapt to such an environment, because it does not always feel confident, and its position in society, in the profession, and even in the family is often unstable. The instability of modern society, in

\footnotetext{
* Corresponding author: kharchenkojv@gmail.com
} 
our opinion, is the absence of a clear system of social norms, the destruction of the unity of cultures, the generation of a qualitatively new "material person".

Although the problem of a changing society at first glance is widely represented in modern philosophical literature, it is nevertheless necessary to analyze the reasons for such cardinal and intense changes, to substantiate in a new way the meaning of the categories of "instability", "chance", "stability" and "necessity".

In this regard, the researcher N. Mironova notes that the models for the formation of new opportunities, patterns of behavior and methods of solving problems that will be offered by Homo Divinans will be very different from the roles offered by the playing manipulators of Homo Ludens, and will differ from those patterns that have been developed Homo Faber. In the crisis zone, near the bifurcation point, where similarity disappears, expectations become intuitive [21]. The author suggested using control models based on the principle of algorithmic "exchange of instabilities" and showed that in the zone of instability, the mental vision of the future Homo Divinans - a presentient person determines the choice of the system at the point of bifurcation [21]. We disagree with the fact that a person lives in conditions of spontaneous influence on it of various external and internal factors. Its existence in a complex society is really influenced by random events, defining its state of mind and world outlook in a new way, value vectors that establish an individual life position, but no less aggressive are: the constantly changing environment in which it interacts with other people, colliding with them own motives, goals and emotional aspirations; crisis phenomena - intensive global migration of carriers of different cultures, traditions and values, as well as economic and financial difficulties giving rise to conflicts. These are all the results of rational strategies. Therefore, the factor of randomness requires additional consideration.

\section{Materials and Methods}

D. Vishnyakov substantiated that non-equilibrium structures arise as a result of irreversible processes in which systemic connections are established by themselves. Probabilistic predictions are simultaneously associated with the necessity and the accidence. The accidental and the necessary always come together. This means that if individual elements change from case to case, then at the same time the picture as a whole reveals stability, which is expressed through the probability [28]. It is important, in this case, to try to roughly measure the frequency of occurrence of random events, since they determine the measure of stability of the entire structure of the social system. That is, such an assessment will serve as an indicator of the viability or non-viability of the system.

In our opinion, the most acceptable for this study is the position of $\mathrm{V}$. Budanov, who determined that deterministic certainty and stochastic uncertainty fade into the background if we are talking about a person, its consciousness, the assessment of its activities. Therefore, we need to learn to control our mind based on the uncertainty and chaos of events and circumstances [4]. "Deterministic certainty" and "stochastic uncertainty" are considered as dualistic categories that reveal the essence of the singular and the multiple in being. Nature and society are also ambivalent in their essence and purposefulness. Note that interactions between individuals are multifaceted in terms of semantic content. Such interactions are based on the principles of multidimensionality of being as such. A person analyzes reality, developing ideal constructs that form its inner world, and also relies on the imperatives of various models of rationality that allow it to survive in the external environment. It weighs reality in terms of culture, art, science, and everyday life. Moreover, the assessment of each event in terms of spiritual and practical value is always incoherent with respect to all other positions. 
From this it follows that, on the one hand, the work of the intellect is associated with the search for patterns in any area of life where planning, forecasting, and mathematical modeling can be used. This helps to eliminate accidents from our rational life, to avoid risks when performing technical tasks. This is the goal of fundamental science - hydrodynamics, physics, chemistry, cybernetics. Attempts to balance deterministic certainty and stochastic uncertainty using the modeling of complex systems lead to the fact that we are able to consider only individual links or characteristics of these systems. This is confirmed by the following positions: Z. Vlahas, J. Pathak, B. R. Hunt, D. Sapsis, M. Girvan, E. Ott, P. Kumutsakos in the process of modeling drew attention to the space-time dynamics of physical systems [29]. H. Arbaby, D. Sapsis carried out modeling and analysis of systems that have a large number of degrees of freedom, possibly combined with a significant amount of uncertainty in the parameters [1]. A. Blanchard, D. Sapsis predicted transient instability and extreme events in arrogant systems [3]. M. Hadji, J. Kluger, D. Sapsis, A. Slocum substantiated that all this is related to the amount of energy expended and noted that one of the advantages of wave energy is higher predictability and the minimum number of changes [13]. However, modeling does not always reflect the essence of such complex abstractions as "space-time", "reality", "artificial intelligence" in their philosophical meanings.

In turn, K. Remik, H.-K. Ju, D. M. McFarland, D. Sapsis, L. Bergman, D. D. Quinn, A. Vakakis have shown that long-term autonomous energy sources are becoming increasingly important for electronic systems - wireless devices such as portable electronics and sensors [26]. H.-K. Ju, D. Sapsis confirmed that a better understanding of system dynamics and optimization of its parameters for the desired performance is a challenge [17]. A. Maida, D. Sapsis, T. Qi, applying the principle of filtering turbulent signal data with the participation of many degrees of freedom in real time, suggested that they would model more accurate predictions of the future state of nature as a complex system [19]. But such models are difficult to apply to being in general, as well as when describing social and spiritual processes.

On the other hand, the intellect is not able to control many random events and not always formal or mathematical logic can solve complex pressing spiritual problems. Human consciousness connects the so-called accidents with the highest principles of being; it is able to oppose the real and the unreal, the random and non-random, as well as the necessary and the natural. Human in the process of realizing or even identifying its presence in being, in society, comes to the understanding that almost every event is more natural than accidental.

However, the points of view of science and religion in relation to random events and phenomena coincide. Science, through mathematics, transforming randomness into regularity, deduces the universal laws of nature, and religion, through theology, completely excludes randomness as such, presenting reality in the image of the result of God's providence, which in the ontological sense is natural and predetermined. Such complex components as intellect and spirit are combined in a person.

Therefore, we can talk about the functional dependence of such planes as spiritual, intellectual, physical, biological, social. Their combination enriches the life of each individual, endows its existence with a special meaning, and promotes the expansion of horizons in the inner microcosm and the outer macrocosm. Each plane of the social, in turn, is multifunctional. Violation of the unity of these planes leads to distortions, violation of their symmetry. This actualizes the study of the random factor as a natural cause, raises the following questions: what gives rise to the instability of society? How events that seem random at first glance are connected?

Based on this, the goal of this study is to conceptualize the phenomenon of interaction in the context of measuring random phenomena and quantities in the unstable social space. 


\section{Results}

Let us analyze the "random" as a factor of instability by means of ontological, phenomenological and transcendental approaches. The ontological method allows us to penetrate into the depths of life, to understand the meaning of "beingness". Key categories of ontology - "reality", "space", "society", "matter", "consciousness" - are inextricably linked. Moreover, "social being" reflects many complex interactions that form social connections, systems, structures, and relationships. Social reality unites two worlds material and ideal. The quality of reality is therefore determined by individual and collective consciousness. The integral structure and dynamics of the development of society depend on the content of information in the mind, reflecting it and the surrounding world. A changing society at each stage of its development demonstrates acceleration, since the human mind sees new details in this "reflection".

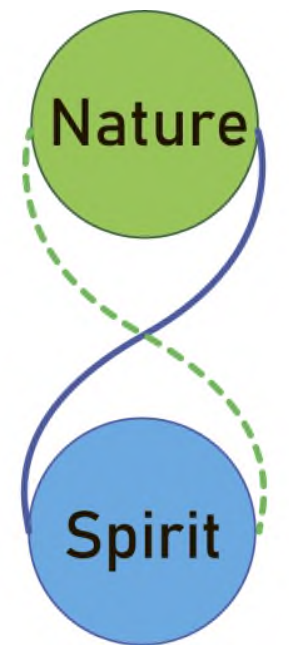

Fig. 1. The essence of the functional dependence of random phenomena and quantities: the contradiction of nature and spirit.

The ontological model proposed, by M. Chernikov and L. Perevozchikova, generalizes the following: the installation of lawfulness, orderliness of things is replaced by the idea of initial chaosogenicity, uncertainty; the attitude about the static, immutability of being is replaced by the idea of self-activity, about constant development, the idea of evolution is generalized; conformity to law, orderliness lose their absoluteness, acquire a local character and appear as a result of the evolutionary process, the result of the ontological transition "chaos-order"; the concept of "potentially possible" acquires an ontological status, the concept of the "space of possible events" is introduced, the real acts as a choice, the implementation of one of the options of the potentially possible is produced; the concepts of "chance" and "probability" acquire an ontological status; the concept of "irreversibility" also acquires an ontological status; the installation of the isolation of objects is replaced by the idea of the fundamental impossibility of complete isolation, of the complex systemic organization of all objects without exception in the natural world; the concept of a causal relationship loses its absolute and acquires a local character; there is an idea of a more general nature of determination in nature [6]. The authors argue that even the material world is impossible to know and observe, since being ceases to be "transparent" for the subject.

Also, to describe an accelerating, unstable society, the concepts of "unstable ontology" and "de-transcending being" are introduced. The author of this idea, D. Shalaginov, defined 
it as discrediting the One in favor of the Many, which supports the binary opposition, the semantic axis One / Many. Thus, the effort to overcome the domination of the One leads to a performative contradiction, because any hypothetical negation of the unity of the world presupposes an implicit opportunity to speak about the whole world as a whole, even in the mode of denying its unity and integrity [27]. Such a world loses its solid foundation; everything becomes fuzzy, coming and going. A person does not want to analyze things and events deeply and such are the new collective ideological attitudes. D. Shalaginov argues that foundations without foundation already exist in unstable ontologies. The One is preserved in one form or another as the universal virtuality of Chaosmos or the General, detranscending being, eliminating its organizing principle in favor of plurality: the universe, having lost its center, acquires a unity devoid of itself, a groundless basis [27]. On the one hand, we are talking about infinity and inexhaustible reincarnations of being and human, on the other hand, about the absence of God in this version of the world today.

The phenomenological method in this study assumes ideation as categorical contemplation, phenomenological reduction and description of random events and phenomena. Based on the judgments of E. Husserl, let us clarify that reduction provides the initial position of the study (return from existing to its being), and the very approach to the subject of research is carried out in a phenomenological "construction" by "sketching out the structures of being" [15]. It is important, first of all, to pay attention to the available phenomenological experience regarding the relationship between random and non-random, the influence of random events and quantities on social systems.

A. Razin's approach is based on the fact that phenomenal experience is an experience generated by a phased understanding of the development of our body and ourselves in specific life situations, of course, and taking into account the influence of the general cultural background. Such an experience endows all the images of our consciousness with a special subjective meaning, an emotional attitude that is present when the images of past perceptions are extracted from our memory [25]. At the same time, the author concludes that not only in the play of images we are ahead of events, we want them to unfold in the direction we want. But this gives the images of consciousness a state of "qualio", in which the images are always associated with our emotional reactions. Phenomenal experience turns out to be no less important than the ability of purely rational reasoning, because the classification of events is associated with it [25]. But a person can change its ideas about things endlessly, and its actions are not always rational. Thus, we can "see" reality as we please.

A. Frolov's phenomenological approach is close to the problem of constituting objective reality in an information society, where: any reality is constituted with the help of one or another information media; there is no reality in itself (more precisely, there is no way to distinguish it from constituted reality); there can be many constituted realities, which gives rise to the problem of their correlation and possible intersection [10]. Emotions, experiences, affects are "layered" on events, which in social reality are the derivatives of irrational actions. This generates random aberrations.

The transcendental method allows to determine the prerequisites for the stability of social systems and to highlight non-random a priori phenomena that are not empirical. The transcendental method of $\mathrm{H}$. Cohen establishes the dependence of the subjective conditions of cognition on the level of cognition actually achieved by the empirical sciences. The transcendental method is used primarily to substantiate ethics, law [7]. Metaphysics, ethics, theology concentrate on morality, spirit, soul, psyche, creativity, thinking as on constructive principles that generate stability and integrity.

E. Husserl's transcendental method presupposes an orientation towards logical principles (highlighting initial experience, initial axioms, methodological principles, logical as such), as well as towards the principles of objectivity in transcendental subjectivity 
(these are types of various foundations and principles of objective-logical connection, types of consciousness (essence consciousness) and the logical laws belonging to them) [14]. The principles of objectively logical connection describe the essence of the functional dependence of various abstract quantities.

Note that the concept of "function" explains the purpose of the principles of interaction, dependence, connection of subjects, objects, quantities, phenomena. "Function" in the broadest sense of the word (from the Latin "functio" - performance, implementation) is presented as: 1) duty, range of activities; 2) purpose, role; 3) a variable quantity that depends on another quantity and changes as it changes [8]. It follows from this that even insignificant transformations at one point or another in space at various systemic levels of the material world can profoundly change its metric properties and generate instability.

For example, an "unstable system" can be represented as a ball placed on top of a convex surface. His balance is unstable. Having started its movement, the ball does not stop and does not return to its original position. There is a classification of unstable systems: 1) spontaneously unstable systems cannot be formed, but when work is expended from the outside, the system can end up in the range of temperatures and compositions limited by the spinodal, and then unstable solutions can exist for some time. Solutions with a concentration other than the critical one can be transferred to the unstable region only with very rapid cooling, so that the system passes through the metastable region without phase separation. All this necessitates the use of such volumes of systems that can be quickly cooled; 2) Condensation-unstable systems are characterized by the formation of aggregates with a strong structure; 3) A thermodynamically unstable system can be kinetically stable. The loss of kinetic stability practically leads to the destruction of the colloidal system and its transformation into a qualitatively different system, for example, a rough dispersion. It is possible to regulate the aggregate and kinetic stability of the system by affecting the process of coagulation of dispersed phase particles, for example, by creating protective layers on their surface by introducing various additives. The stability of colloidal systems can also change by the formation of solvation layers of solvent molecules around dispersed particles. By freezing unstable systems, they can be converted into stable ones, since during supercooling, the time required to establish a normal equilibrium state (relaxation time) can become practically infinite. Consequently, a structurally unstable system cannot be stable for any values of the coefficients [22]. That is, so far only physics, chemistry and biology most fully describe individual technical characteristics, principles of development and functioning of unstable systems through the mathematical language.

In the spiritual world, a careless word or action, or, on the contrary, a feat, impulse, dedication, can radically change the individual fate or even the fate of millions of people, changing the general properties of the system, its image and the meaning of its existence in the future. On the one hand, logic can facilitate the solution of any practical problem. On the other hand, in the sphere of the Spirit, it is powerless, because there "everything is absurd."

Human logic and its laws, on the basis of which the ratio of quantities and their values is isolated, is of particular interest from the point of view of the functional dependence of phenomena, events and quantities. In the science of logic, the term "function" means the correspondence between the variable quantities $\mathrm{x}$ and $\mathrm{y}$, as a result of which each value of the quantity $\mathrm{x}$ (independent variable, argument) is associated with a single value of the quantity y (dependent variable). This correspondence is written as the expression $y=f(x)$ [16]. The key purpose of various models of logic in modern mathematical logic is: effective ordering of life, knowledge; optimal search and processing of information; setting constructive goals; forecasting the distant future. Logic also helps to develop valuesemantic life positions and to model new rational methods. The operation of logical laws is reflected in all areas of everyday life. 
For example, in architecture, "function" is a term that defines the purpose of premises, buildings, structures or any of their parts [2]. Almost every item used in everyday and professional activities is designed for specific purposes and is often multifunctional.

In the twentieth century, in the architecture and art industry there is a trend of functionalism, the main thesis of which ("form follows function"), that is, its main principle is the mandatory, strict conformity of the form of buildings and structures and the processes (functions) occurring in them [2]. Thus, structures, objects, things bring additional comfort to everyday life, and they all perform a specific function. Today, the amount of necessary things is a variable quantity; therefore, enterprises are producing more and more resources to meet the growing needs of consumers. Only in a stable society benefits are distributed more or less proportionally. This makes it possible to plan for the future, develop spiritually.

Based on the above, we emphasize that functional dependence is a form of stable relationship between phenomena or quantities, in which a change in some phenomena causes a quite definite change in others [9]. On the one hand, the laws of nature regulate the viability of various material formations, form their structure.

On the other hand, a person acts within the framework of natural, social, legal laws, but its actions are always individual and have a creative connotation. It is always guided by something in its actions (personal motives, career preferences, individual goals and strategies), but only it is able to feel the ontological meaning of being, to "rise" to it. Moreover, it would seem that logic can make life more stable and predictable, but its use as a tool in the field of modern technologies, on the contrary, can contribute to the generation of fluctuations in society. That is, chaos, social cataclysm, conflict can be coupled with external thoughtful and exclusively logical actions. And then chaos, like order, is natural, then seemingly random events are not accidental.

A random event is a subset of the set of outcomes of a random experiment; when a random experiment is repeated many times, the frequency of occurrence of an event serves as an estimate of its probability. And a random phenomenon is a phenomenon that, when the same experience is repeated several times, proceeds somewhat differently each time, and which is also due to a very large number of factors [12]. Consequently, society can be viewed as a system of historically established relations, which effectively functions thanks to artificially introduced laws, norms, rules, and a person as a creature that seeks more rational actions, since for it the concept of the future is more significant than the present or even the past. It is used to planning the future and endlessly varying its images. As a result, it can be stated that in any case, any event or action, although it strives for general normativity, has an infinite number of variations in self-expression.

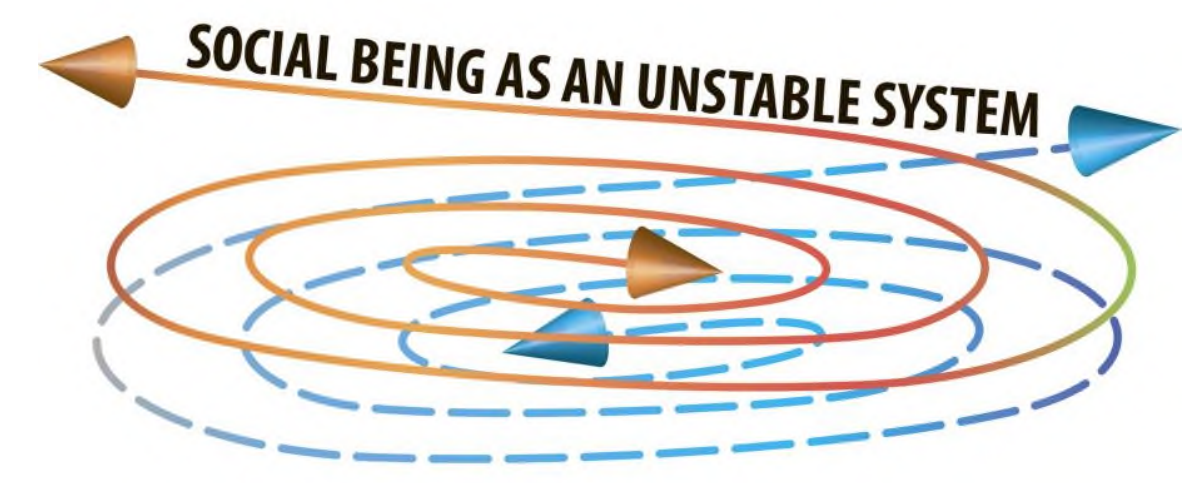

Fig. 2. Social being in the logic of instability. 
The logic of instability as a factor generating random events can be described through functional and probabilistic approaches. The functional approach contributes to the systemic study of random phenomena and quantities as a structurally split integrity, in which each quantity as an element of the structure has a specific functional purpose, and each event has an additional semantic load. This method is necessary for the study of mechanisms that ensure sustainability in society. The structural-functional approach of $\mathrm{T}$. Parsons is also used, which describes the abstract theory of social systems, with key functions: adaptive, goal-achieving, integrative and the function of regulating the latent tensions of the system. The main structural formations of the social system are not socioeconomic structures, but values and norms. The main mechanism that ensures the effective functioning of the system is the process of socialization of individuals, during which the norms and values existing in society are assimilated, and various forms of deviant behavior are regulated with the help of social control [23]. The author offers tools for stabilizing and balancing social relations using value and normative mechanisms for regulating human activity.

The probabilistic method determines the moment of occurrence of random events, and also provides modeling of the probability of the development of an event according to an alternative scenario, fixes the multiplicity of scenarios and intersecting chains of random events.

\section{Discussion}

An effective approach is the approach of Y. Tchaikovsky, who substantiated that logical probability belongs to the range of phenomena where there is no speech about frequency, and moral probability generally refers not to phenomena, but to opinions. Probabilistic randomness (stochasticity) has a rigid invariant - probability - and therefore it is a step between deterministic and truly random phenomena. All forms of them are characterized by the absence of stable frequencies, but almost all have some kind of invariants and thus admit a theoretical description [5]. The author emphasizes that if randomness is more complicated, then the procedure for identifying conditional or transition probabilities may turn out to be too long and fractional, and here it is more convenient to introduce the concept of a fractal. The fractal-generating rule itself can be simple or compound, deterministic or not. In short, it is always important to understand what kind of randomness we are dealing with, and the answer is usually far from simple. Apparently, any interaction between random acts can be represented as a violation of the symmetry of randomness, but not vice versa [5]. That is, deeply analyzing random events, the mind often translates them into the rank of non-random, that is, it balances on the verge of mathematical and transcendental logic.

In mathematics, the theory of probability is introduced as a means of ordering random events, revealing their functional dependence. That is, in fact, it normalizes, legitimizes the category of randomness, defining its more or less natural characteristics. Thus, it, in turn, explains random numbers as numbers generated by a random process that generates any number in such a way that each of the ten digits $(0,1,2 \ldots 9)$ has a different possibility of being in its composition. In general, the probability of occurrence of any particular sequence of random numbers consisting of $\mathrm{n}$ digits is $0.1 \mathrm{n}$. In this case, a random variable is called a value that, as a result of the test, will take one and only one numerical value, depending on random factors and unpredictable in advance. Random variables are usually denoted by $\boldsymbol{X}, \boldsymbol{Y}, \boldsymbol{Z}$, and their values are denoted by the corresponding small letters with subscripts, for example, $\boldsymbol{x} \boldsymbol{1}, \boldsymbol{y} \boldsymbol{1}, \boldsymbol{z} \mathbf{1}[12]$. Various numerical values are significant when describing random events and phenomena. There are some similarities between random events and random phenomena. 
Modern cybernetics has also created special mathematical constructs and tools for processing and storing information in the field of artificial intelligence, which make it possible to coordinate an increasing amount of data. At this stage, a quantum computer will theoretically be able to manage the maximum number of complex processes and develop optimal solutions for any complex system.

If we consider the system in a purely technical sense of the word as an ideal model, then it can be adjusted under any circumstances, only by modernizing management tools and functional characteristics taking into account time. A. Rakitov contrasted the process and the law of functioning and emphasized that such an approach has as its prerequisite the distinction between two aspects of systems research. On one condition, the development of the system is brought to the fore, that is, a certain time sequence of the formation of the object. On another condition, an analysis of the functioning of an already established readymade system is provided. It is easy to see that both of these aspects mean dynamic, that is, working, and not static systems [24]. A well-established stable system that has been functioning for a long time is always rather static. In order to keep a dynamic system stable, it is necessary to react to any of its modifications and accordingly apply modernized technologies to it. That is, it requires the use of drifting rules and exclusively scientific approaches in relation to itself.

A. Rakitov rightly asserts that at the functional level of consideration of phenomena and quantities, not separate sentences act as components of the system object "science", but functional groups, the number of which is fixed, he proposed to call "components of the composition of science" [24]. The number of such functional groups may or may not be fixed.

E. Mendelssohn explained that in mathematical logic complete connective systems are understood as any propositional form containing $\mathrm{n}$ propositional letters, which generates the corresponding truth function of $\mathrm{n}$ arguments. The values of these arguments and functions are $\boldsymbol{T}$ ("truth") or $\boldsymbol{F}$ ("false"). Logically equivalent forms generate the same function [20]. This is where the complexity arises; we cannot say that all truth functions are generated in this way. However, mathematical logic, trying to eliminate this complexity, creates a special "logical polysemantics".

E. Mendelssohn argues that such logics can generate their functional independence. Multi-valued logics are a subset $\boldsymbol{X}$ of the set of all axioms of a given axiomatic theory, which is called independent if some formula from $\boldsymbol{X}$ cannot be derived using the rules of inference from axioms that are not included in $\boldsymbol{X}$ [20]. Logical polysemantics gives rise to a "topological" construction of arguments.

E. Mendelssohn, using the example of "quantifiers", showed that there are types of logical reasoning that cannot be substantiated within the framework of the propositional calculus. The correctness of these inferences rests not only on the truth-functional relations between the sentences included in them, but also on the internal structure of the sentences themselves, as well as on the understanding of expressions such as "all", "everyone" [20]. This means that the truth-functional connections between logical constructions can be destroyed due to an infinite number of variables (arguments, statements) and any random new logical construction (in fact, an infinite number of variants of logical constructions).

We agree with I. Lakatos that the endless expansion of concepts destroys meaning and truth. For any sentence, there is always some rather narrow interpretation of its terms, which turns out to be true, and some wide enough, which turns out to be false. Which interpretation is supposed and which is not depends, of course, on individual intentions [18]. It can be concluded that the theory of probability contributes, first of all, to the establishment of approximate boundaries between clear and fuzzy logical systems.

B. Gerasimov, G. Grabovsky, N. Ryumshin emphasize that the interpretation of the degree of truth, like the membership function, can be as follows: the degree of truth is the 
probability that the decision-maker will call the statement true. Fuzzy logical expressions (or fuzzy formulas) differ from ordinary ones by the presence in them of linguistic and fuzzy variables and relations (predicates) [11]. All of this gives rise to fuzzy algorithms and fuzzy graphs. The authors contrast the algorithm and the fuzzy algorithm.

By an algorithm, they mean a precisely formulated rule of action (program), indicating how and in what sequence, this rule must be applied to the original data of the problem in order to obtain its solution. The characteristics of the algorithm are: a) determinism (certainty) as the unambiguity of the results of the process with given initial data; b) discreteness of the process and its dissection into separate elements of the action; c) massiveness and the ability to select the initial data for the algorithm from a certain set of data, that is, the algorithm must provide a solution to any problem from the class of similar problems [11]. This algorithm has a logical consistency and structural clarity.

A fuzzy algorithm, according to their observation, is determined by an ordered set of fuzzy instructions (fuzzy statements) containing concepts formalized by fuzzy sets [11]. Fuzzy sets are used in problems of macro-design of complex systems and micro-design of their structures.

B. Gerasimov, G. Grabovsky, N. Ryumshin propose to use two approaches when designing complex systems. The first (macro-design): considers the choice of physical principles of implementation, the organization of functions and the structure of the system as a whole; involves clarifying the goals that the system should serve and the main tasks it solves, studying the properties of the external environment and determining their impact on the system, as well as justifying the technical requirements for the system and forming the appearance of the system [11]. The second (micro-design, or internal design of the system) is associated with technical solutions for the main elements, their design and parameters, operating modes. The work on the macro-design of the system begins with the formulation of problematic issues containing three main sections: a) a clear definition of the goals of creating the system and the range of tasks it solves; b) a list and characteristics of factors acting on the system to be developed; c) selection of one or more indicators of the quality of the system [11]. Such systems can be understood as structurally stable.

\section{Conclusion}

All of the above allows us to draw the following conclusions: in stable systems fewer random events appear and in unstable systems most or even all of them can be random. In sustainable systems changes are predictable and logical; they do not cause tangible shocks, since they are technically removable. In unstable systems, change is continuous. This generates chaotic oscillations of the entire system. In this case, events can be perceived rather as consequences that cannot be prevented.

In society, if human actions are not coupled with the principles of morality, ontological laws, thoughtful and balanced political strategies, reflected in the thousand-year history of human spiritual and intellectual experience, then the system will seem stable for some time. It will require the introduction of additional instruments of control and power. Then fluctuations will necessarily appear. In this case, the spontaneous course of events will no longer be controlled. These stochastic processes will become not the causes, but the consequences of illegal actions in the past. If such actions are carried out in the present, the consequences will necessarily manifest themselves in the future.

On the contrary, if humanity acts constructively, in accordance with its high moral nature, then the system will be stable and stable for a long time. It is obvious that stability and instability are consistently established in various modern political systems. In society, instability is most often associated with ineffective management, weak or immature institutions of political power. This can be seen in the example of various local conflicts. 
In the context of the foregoing, we agree with the opinion of K. Jung that today's civilizational life requires a concentrated, directed functioning of consciousness, and this entails the danger of a strong disconnection from the unconscious. The further through directed functioning we can move away from the unconscious, the more active the powerful counter position lurking in it will be, and its breakthrough can have very undesirable consequences [30]. A person can introduce a system into an unstable state, even under the condition of effective management, when his ill will or personal interest can create chaos after a certain time.

An unstable system does not return to the state of equilibrium, from which it left for one reason or another, but continuously moves away from it or makes unacceptably large fluctuations around it. Unstable systems are practically unsuitable for normal life in society. They are used only under artificial conditions. It is important, therefore, to understand that the functional dependence between random phenomena and quantities under conditions of social instability is possible as stability of a different kind. Randomness and illogicality are derivatives of certain rational actions in the past.

\section{References}

1. H. Arbabi, T. Sapsis, Bulletin of the American Physical Society 11/25 (2019)

2. P.P. Bezrodnij. Arhitekturni termini: Korotkij rosijs'ko-ukraïns'kij slovnik: Dovidnikovij posibnik (Vishcha shkola, K., 1993)

3. A. Blanchard, T. Sapsis, SIAM Journal on Applied Dynamical Systems 18(2), 1143 $1162(2019)$

4. V.G. Budanov et al, Razum. Postneklassika 2, 66-74 (2016)

5. Yu.V. Chajkovskij, O prirode sluchajnosti. Monografiya V. 27 (M., 2004)

6. M.V. Chernikov, L.S. Perevozchikova, Filosofiya i obshchestvo 1, 95-110 (2019)

7. H. Cohen, Kants Theorie der Erfahrung (Dümmler, Berlin, 1885)

8. Filosofskij slovar' (A.S.K., K., 2006)

9. M.M. Rozentalya, P.F. Yudina, Filosofskij slovar' (Politizdat, M., 1963)

10. A.V. Frolov, Filosofiya i obshchestvo 1, 18-38 (2019)

11. B.M. Gerasimov, G.G. Grabovskij, N.A. Ryumshin, Nechetkie mnozhestva v zadachah proektirovaniya, upravleniya i obrabotki informacii (Tekhnika, K., 2002)

12. B.V. Gnedenko, Kurs teorii veroyatnosti. Izdanie 5 stereotipnoe (Izdatel'stvo «Nauka»; Glavnaya redakciya fiziko-matematicheskoj literatury, M., 1969)

13. M. Haji, J. Kluger, T. Sapsis, A. Slocum, Ocean Engineering Journal 169, 673-681 (2018)

14. E. Husserl, Zur Auseinandersetzung meiner transzendentalen Phänomenologie mit Kants Transzendental philosophie (Husserliana, Bd. 7. Den Haag, 1956)

15. E. Husserl, Logische Untersuchungen (Husserliana, Den Haag, 1984)

16. A.A. Ivin, A.L. Nikiforov, Slovar' po logike (Gumanitarnyj izdatel'skij centr VLADOS, M., 1997)

17. H.-K. Joo, T. Sapsis, Journal of Ocean and Wind Energy 2(2), 65-72 (2015)

18. J. Worrall, E. Zahar, Lakatos. Proofs and Refutations (Cambridge, University Press Cambridge, 1976)

19. A. Majda, D. Qi Sapsis, Proceedings of the National Academy of Sciences 111 (2014) 
20. E. Mendelson, Introduction to Mathematical Logic (Queens College of the City University of New York. Chapman \& Hall London - Weinheim - New York -Tokyo Melbourne - Madras, 1997)

21. N.I. Mironova, Social'naya dinamika: metamorfozy samoorganizacii $i$ upravleniya (OAO «Chelyabinskij Dom pechati», Chelyabinsk, 2005)

22. Neustojchivaya sistema. Bol'shaya enciklopediya nefti $i$ gaza http://www.ngpedia.ru/id430230p1.html

23. T. Parsons, The Social System. Glencoe (Free Press, Ill., 1951)

24. A.K. Rakitov, Kurs lekcij po logike nauki (Izdatel'stvo «Vysshaya shkola», M., 1071)

25. A.V. Razin, Etika iskusstvennogo intellekta. Filosofiya i obshchestvo 1, 57-73 (2019)

26. K. Remick, H.-K. Joo, D.M. McFarland, T. Sapsis, L. Bergman, Quinn, A. Vakakis, Journal of Sound and Vibration 333, 3214-3235 (2014)

27. D.S. Shalaginov, Preodolenie edinstva i ontologicheskaya nestabil'nost'. Filosofskie nauki 5, 67-79 (2015)

28. D.V. Vishnyakov, Ideya nestabil'nosti u I. Prigozhina. Prepodavatel' XXI vek 2, 258263 (2013)

29. Z. Vlachas, J. Pathak, B.R. Hunt, T. Sapsis, M. Girvan, Forecasting of Spatio-temporal Chaotic Dynamics with Recurrent Neural Networks: a comparative study of Reservoir Computing and Backpropagation Algorithms (2019)

30. K.G. Yung, Sinhroniya: akkauzal'nyj ob"edinyayushchij princip. (AST MOSKVA, M., 2010) 